\title{
Porcelain shards from Portuguese wrecks: Raman spectroscopic analysis of marine archaeological ceramics
}

\author{
Elizabeth A. Carter ${ }^{1,2}$, Michelle L. Wood ${ }^{1,2}$, Danita de Waal ${ }^{3}$ and Howell G. M. Edwards ${ }^{4}$
}

\begin{abstract}
Raman spectroscopic analysis of shards recovered from two Portuguese shipwrecks, the Santo Espirito (1608) and the Santa Maria Madre de Deus (1643), believed to be carrying porcelains of the Ming period have revealed some interesting and novel results that inform historical ideas of porcelain production. The porcelain body of two of the four shards from the Santa Maria Madre de Deus were found to contain anatase, a low temperature polymorph of titanium dioxide, and $\beta$-wollastonite a mineral characteristic of soft-paste porcelains that are made at medium-temperature firing conditions. Previously, $\beta$-wollastonite has been found in a range of sixteenth to nineteenth century European porcelains but this is the first report of its detection in porcelain believed to be from the Ming period. These same shards exhibited unusual spectral features that were attributed to the resonance enhancement of rare earth elements that resulted from excitation using a near-infrared source.
\end{abstract}

Keywords: Raman spectroscopy, $\beta$-wollastonite, Anatase, Porcelain, Ming period

\section{Background}

The application of Raman spectroscopy as a non-destructive technique for the analysis and characterisation of ancient ceramics from museums and archaeological excavations $[1,2]$ has produced extensive literature which extends over several thousand years of civilisation from Egyptian faience of the eighteenth dynasty (ca. 1400 BC) through to the fine European and Chinese porcelains of the fifteenth to nineteenth centuries. The range of materials investigated includes tin-glazed earthenwares, mediaeval terracotta roof tiles, majolica and bone Chinas from which it has been possible to deduce the salient features of the ceramic bodies, glazes and the applied pigments where appropriate [3-7]. The non-destructive analysis of ceramics poses several challenges for spectroscopists because of their composite nature, where the sintered grain and domain sizes range from a few microns to about $500 \mu$, the presence of crystalline and glassy phases

\footnotetext{
*Correspondence: elizabeth.carter@sydney.edu.au

1 Vibrational Spectroscopy Core Facility, The University of Sydney, Sydney, NSW 2006, Australia

Full list of author information is available at the end of the article
}

along with unreacted starting components, and the inhomogeneity of the ceramic matrices arising from diverse processing technologies, firing sequences and kiln temperatures. Where ancient records exist from porcelain factories, the scale of the problem can be assessed; for example, at the Meissen factory in the eighteenth century there were more than five recorded porcelain bodies which were recommended for use at different levels in the firing kilns to account for temperature inhomgeneities [8]. Another problem of particular significance for Raman spectroscopic analysis arises from the recovery of broken ceramics from archaeological excavations, where the assimilation of fluorescent materials from the burial environment has occurred which often has resulted in high levels of background fluorescent emission and resultant poor quality Raman spectral response.

Nevertheless, the opportunity for the application of non-destructive analytical techniques to the characterisation of ceramics from archaeological excavations is an important one when it is appreciated that much of the earlier chemical characterisation reported often involved the complete destruction of the specimen, as in the classic studies of Eccles and Rackham [9], who required the 
sacrifice of a whole cup, saucer or a plate from early porcelain services in the derivation of the chemical composition of early English porcelains.

In the sixteenth and seventeenth centuries, the native European glazed terracotta, tin-glazed earthenware and majolica had to compete unsuccessfully with imports of hard paste (pate dure) porcelains from China; the latter had a beautiful translucency, were thinly potted and possessed a white, smooth surface which readily exhibited applied decoration to the maximum effect. The secret was the addition of kaolin to the china paste before firing. It took until the mid-eighteenth century before European china factories such as Sevres, Meissen, Worcester and Chelsea could compete with their soft paste (pate tendre, containing calcined bone ash and glass frit) and hard paste (pate dure) versions and meet the increasing demand in society for the new ceramics. From 1498, when Vasco de Gama sailed around the Cape of Good Hope, the emergence of Portuguese and Dutch marine exploration gave rise to a vast trade in spices, ceramics and other goods with Asia, and Chinese porcelains of the Ming period (1368-1644) were much desired in Europe. Portuguese carracks and navetas returning home from China were often overloaded and in poor condition after a long and arduous outward voyage and a significant number perished in the stormy and treacherous seas off Southern Africa. It is known that at least 15 large Portuguese ships sank in this area before 1650, from the records of survivors [10]; nine of these have been identified by field archaeologists and two of these form the subject of the current investigation, namely, the Santo Espirito, which sank in 1608 in Morgan's Bay, Eastern Cape, and the Santa Maria Madre de Deus, which sank in 1643 in Bonza Bay, East London. Both ships were carrying cargoes of Ming porcelain and five shards recovered by marine archaeologists from the wrecks have been made available for Raman spectroscopic analysis.

\section{Experimental}

Five Chinese porcelain shards (Fig. 1) from the two Portuguese wrecks, dating from 1608 and 1643, which places the ceramics firmly in the later Ming period (1368-1644) described as Wanli or immediately post-Wanli, were subjected to Raman spectroscopic analysis. The shards form part of the J.A. van Tilburg Collection at the University of Pretoria. Shards \#1 to \#4, were from the Santa Maria Madre de Deus and, shard \#5, was from the Santo Espirito; the shards presented several differences in appearance and are described below:

1. Greyish white porcelain body with pale blue decoration, $30 \mathrm{~mm} \times 16 \mathrm{~mm}$; unglazed.

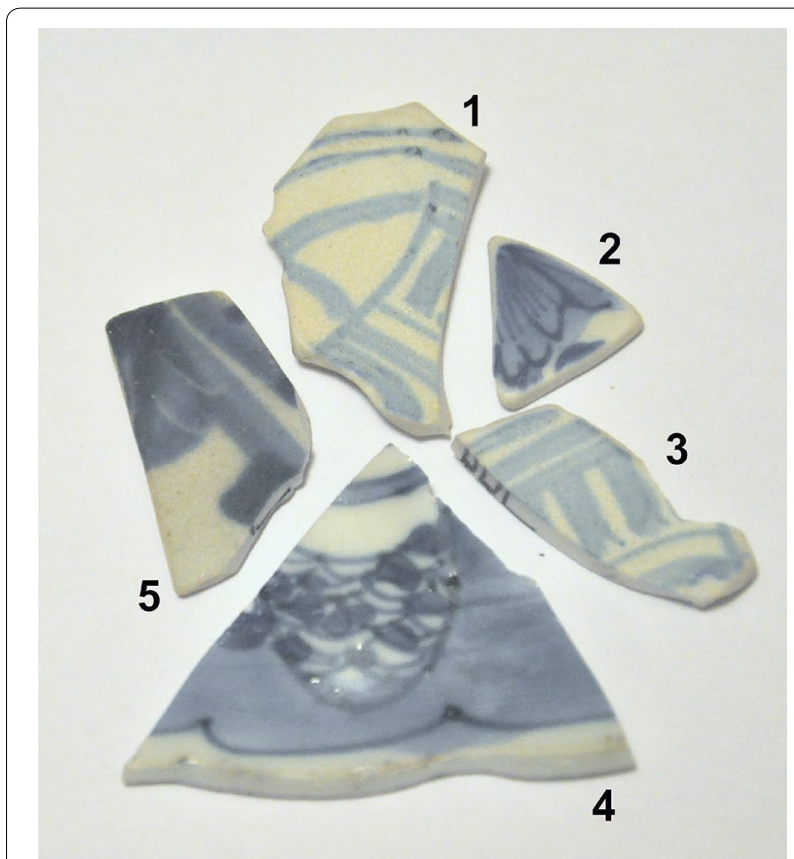

Fig. 1 Five Ming period porcelain shards from the shipwrecks of the Portuguese carracks, Santo Espirito (1608) and Santa Maria Madre de Deus (1643); shards \#1-4 were recovered from the Santa Maria Madre de Deus and shard \#5 came from the Santo Espirito

2. Creamy white porcelain body with pale blue decoration, $15 \mathrm{~mm} \times 13 \mathrm{~mm} \times 15 \mathrm{~mm}$; glazed.

3. Greyish white porcelain body with pale blue decoration, $25 \mathrm{~mm} \times 9 \mathrm{~mm}$; unglazed.

4. White porcelain body with dark blue decoration, $33 \mathrm{~mm} \times 40 \mathrm{~mm} \times 35 \mathrm{~mm}$; glazed.

5. White porcelain body with dark blue decoration, $26 \mathrm{~mm} \times 15 \mathrm{~mm}$; glazed.

Several opportunities for spectral sampling were presented, offering illumination of the blue pigment(s), the glaze and the porcelain body both on the upper and lower surfaces and also on the broken edges of the shards.

Raman spectra were collected using a Renishaw Raman inVia Reflex Microscope (Renishaw plc, Wotton-underEdge, UK), equipped with an air-cooled charge-coupled device camera. The spectrometer was fitted with holographic notch filters and two gratings $(1200 \mathrm{~mm}$ per line (visible), $2400 \mathrm{~mm}$ per line (near infrared)). The attached microscope was a Leica DM LM and was equipped with three objectives $(\times 50 / 0.75 \mathrm{NA}, \times 20 / 0.40 \mathrm{NA}, \times 5 / 0.12 \mathrm{~N}$ A) and a trinocular viewer that accommodated a video camera, allowing direct viewing of the sample.

Sample excitation was achieved using a NIR laser (TOPTICA Photonics AG, Graefelfing, Germany) emitting at $785 \mathrm{~nm}$. The spectrometer was controlled using a computer with instrument control software (Renishaw 
WiRE Versions 3.0 and 4.2). Spectra were recorded using the $50 \times$ objective over the spectral range of $3200-100 \mathrm{~cm}^{-1}$ or $1800-100 \mathrm{~cm}^{-1}$ with the accumulation of scans, exposure and a laser power modified to suit each sample. Spectra were not corrected for instrument response.

\section{Porcelain manufacture in China}

The analysis of archaeological ceramics provides some special challenges because of their composite nature and size range of the microstructural material; sintered grains and domains range from several microns up to about $500 \mu$. Crystalline and glassy phases can occur together, along with unreacted starting materials and the molecular composition of the porcelain body and of the applied glaze is critically dependent upon the processing technology, firing sequence and kiln temperature. With regard to the latter parameter, inhomogeneity in the temperature of ancient kilns could give rise to variations in molecular composition of the resultant porcelain at the microscopic level.

Porcelain was first made in China during the Song Dynasty (960-1279 AD) and this gave rise to the very desirable, classic blue and white porcelains of the Ming Dynasty (1368-1644 AD); the major production was at Jingdezhen, which was fitted with large wood-burning dragon kilns that could take tens of thousands of items in a single firing. Towards the end of the Ming Dynasty, when the porcelain shards studied here were made, the kilns were modified into ovoid shapes which facilitated the attainment of a higher firing temperature of $1350{ }^{\circ} \mathrm{C}$ with the choice of a reducing or oxidising atmosphere. This produced a dramatic effect on both the pigment colours and body of the porcelains; white wares were made from clays that were low in iron, but in the presence of iron, ceramics fired in an oxidising atmosphere were red whilst those fired in a reducing atmosphere were grey.

The kaolinite clay used to make porcelain is composed of alumina and silica with added water to confer malleability; on heating to $\sim 500-600{ }^{\circ} \mathrm{C}$ water is expelled from the lattice leaving a meta-kaolin phase comprising $2 \mathrm{Al}_{2} \mathrm{O}_{3} \cdot 4 \mathrm{SiO}_{2}$. At $925^{\circ} \mathrm{C}$ an exothermic reaction results in the formation of a spinel, $2 \mathrm{Al}_{2} \mathrm{O}_{3} \cdot 3 \mathrm{SiO}_{2}$, where one in four of the silica units are removed from the lattice. Above $1050{ }^{\circ} \mathrm{C}$ this structure transforms into mullite, with conversion of the expelled silica into cristobalite; if feldspar is present in the ingredients then this now melts at $1010-1100{ }^{\circ} \mathrm{C}$ and dissolves the cristobalite to produce a viscous liquid which cements the quartz crystals together. A decrease in viscosity appears at $1200-1250{ }^{\circ} \mathrm{C}$ which results in the filling of the particle interstices. Then finally at $1280{ }^{\circ} \mathrm{C}$, large crystal formation of mullite results in the production of a less viscous state in which the quartz is dissolved-giving a true porcelain. In China, the availability of a porcelain stone called petuntse, which contained a primary clay mineral, sericite, and the aluminosilicate feldspar and quartz, when mixed with an aluminosilicate kaolin clay gave the required ingredients and sustainability of high temperature firing that could produce the beautiful porcelain product that was so much in demand in Europe [11, 12]. A typical composition of hard paste porcelain was kaolin 75\%, feldspar (anorthite) 10\% and quartz sand $15 \%$.

\section{Results and discussion}

The spectroscopic analysis of porcelains can not only determine the molecular composition of the body and glaze but also reveal some information about the production process and kiln firing temperature range in which they were made. Raman spectra of the shards from the early seventeenth century Portuguese shipwrecks, see Figs. 2, 3, 4, 5, 6 and 7, were indicative of several important features of porcelain manufacture as highlighted in the above account; generally, glassy ceramic materials can be classified [13] according to the Q-components of $\mathrm{SiO}_{4}$ tetrahedra in the material composition:

\section{$\mathrm{Q}^{0}: \quad$ monomeric $\mathrm{SiO}_{4}$ groups, wavenumber range $800-850 \mathrm{~cm}^{-1}$; \\ $\mathrm{Q}^{1}: \quad \mathrm{Si}_{2} \mathrm{O}_{7}$ groups, wavenumber $\sim 950 \mathrm{~cm}^{-1}$; \\ $\mathrm{Q}^{2}$ : $\quad$ silicate chain, $\mathrm{Si}_{3} \mathrm{O}_{9}$ groups, wavenumber range $1050-1100 \mathrm{~cm}^{-1}$;}

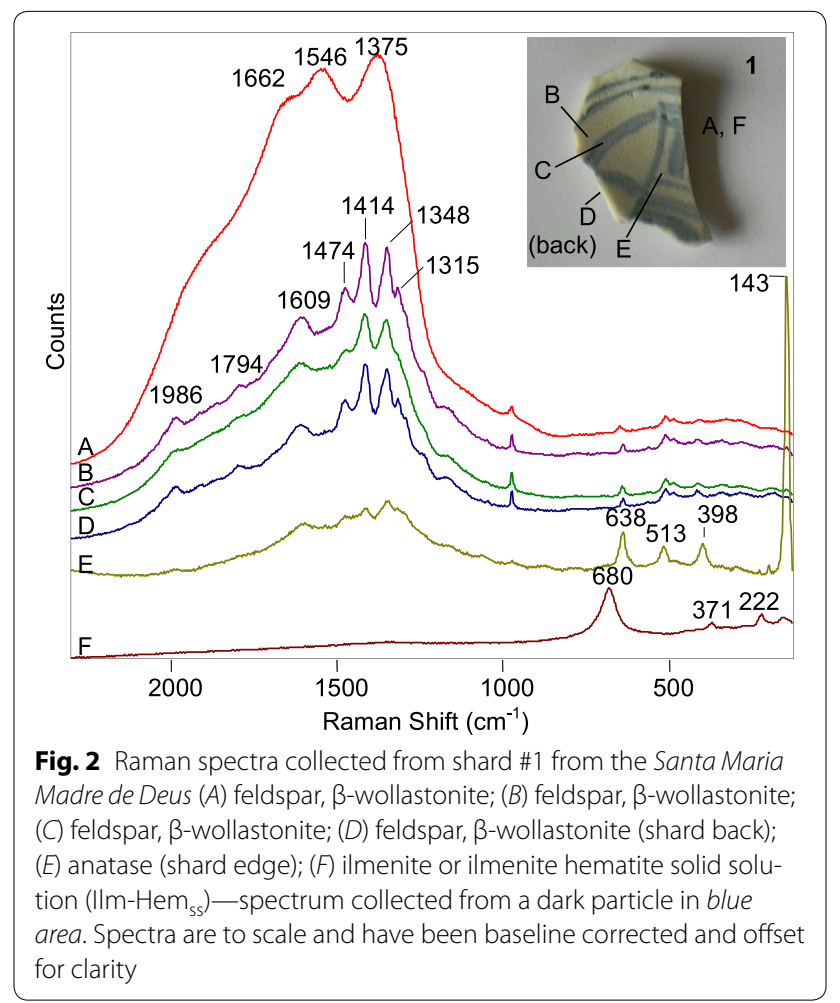




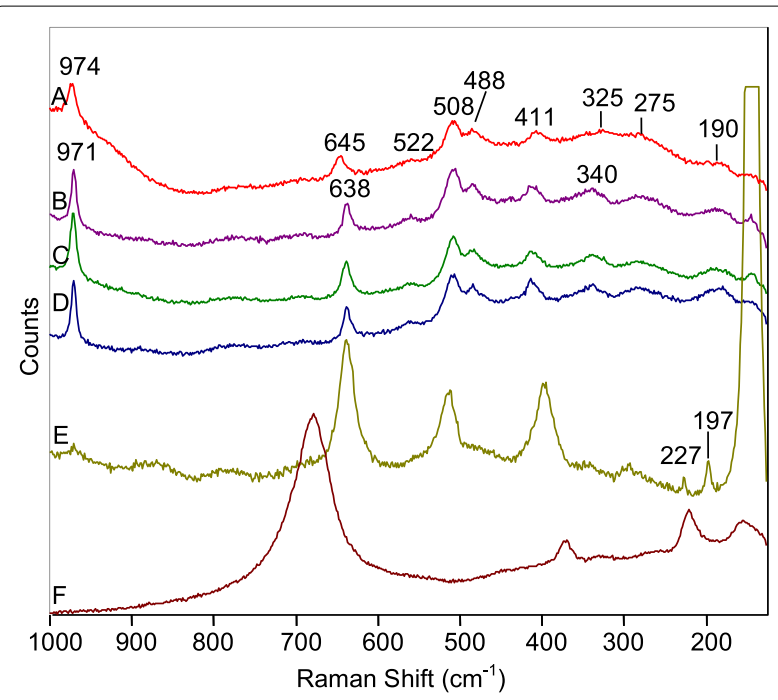

Fig. 3 Expansion of the $1000-125 \mathrm{~cm}^{-1}$ spectral region presented in Fig. 2. Spectra are to scale, baseline corrected and offset for clarity

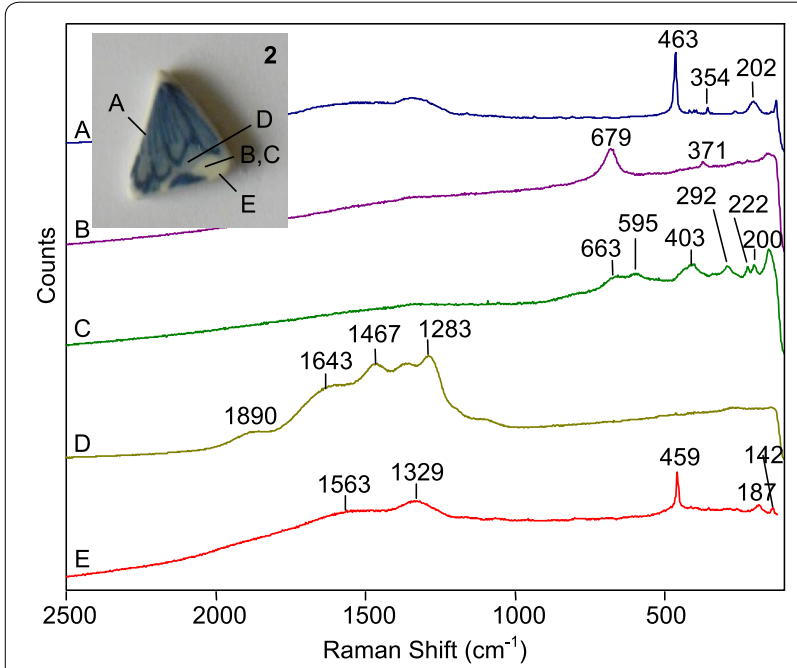

Fig. 4 Raman spectra collected from shard \#2 from the Santa Maria Madre de Deus. A a-Quartz (shard back), (B) ilmenite or ilmenite hematite solid solution (IIm-Hem ${ }_{\mathrm{ss}}$ ) - dark particle in white area on topside of sample, $(C)$ hematite - dark particle in white area, $(D)$ luminescence from REE - light blue area, (E) carbon, a-Quartz, anatase - (shard edge)

$\mathrm{Q}^{3}: \quad$ silicate sheets, $\mathrm{Si}_{4} \mathrm{O}_{11}$ groups, wavenumber $\sim$ $1100 \mathrm{~cm}^{-1}$;

$\mathrm{Q}^{4}: \quad \mathrm{SiO}_{2}$ and tectosilicates, wavenumber range $1150-1250 \mathrm{~cm}^{-1}$.

In $\alpha$-quartz a well-defined structure results in a strong, sharp Raman band, the $\mathrm{SiO}_{2}$ bending mode of $\mathrm{A}_{1 \mathrm{~g}}$ symmetry at $464 \mathrm{~cm}^{-1}$. This broadens in fused silica and

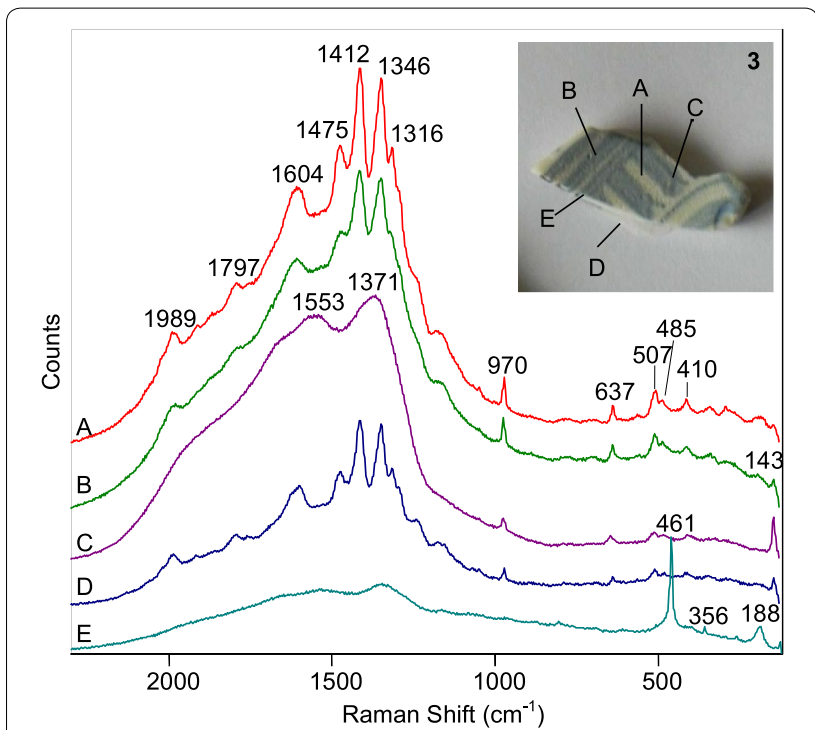

Fig. 5 Raman spectra collected from shard \#3 from the Santa Maria Madre de Deus. 4 (A) Feldspar, $\beta$-wollastonite; (B) feldspar, $\beta$-wollastonite; (C) feldspar, $\beta$-wollastonite; ( $D$ ) feldspar, $\beta$-wollastonite, anatase, (shard back); (E) quartz — shard edge. Spectra are to scale and have been baseline corrected and offset for clarity

shifts to higher wavenumber when submitted to mechanical stress. A useful parameter for glazed porcelains is the degree of polymerisation (DP) which can be obtained from the relative band intensities of the broad envelopes at 500 and $1000 \mathrm{~cm}^{-1}$; this has been elegantly summarised by Colomban and co-workers [7, 8, 13]. In general, the $A_{500}: A_{1000}$ band intensity ratio is in the range of $0.8-1.1$ for soft-paste porcelains which have been fired between $800-900{ }^{\circ} \mathrm{C}$ and $1.5-7.0$ for hard paste porcelains reflecting their higher firing temperature of between 1100 and $1400{ }^{\circ} \mathrm{C}$.

\section{Shards \# 1 and \#3 from the Santa Maria Madre de Deus}

The blue pigment on Ming porcelain has previously been identified [14, 15] as cobalt blue (cobalt aluminate), $\mathrm{CoAl}_{2} \mathrm{O}_{4}$, which had been known in China from the Tang dynasty but discovered in Europe only in the eighteenth century, when it was known as Thenard's blue [16]. Here, the Raman spectra of the blue pigment found on the unglazed porcelain shards \#1 and \#3, shown in Figs. 2, 3 and 5, would suggest the presence of cobalt blue with the characteristic doublet of cobalt aluminate observed at $\sim 488$ and $508 \mathrm{~cm}^{-1}$; the spectrum is similar to that of a shard recovered from the wreck of the São Gonçalo, which sank in 1630 in Plettenberg Bay, Western Cape [10]. However, it is worthwhile noting that these same features are also observed in the Raman spectra of feldspar minerals and the $488 / 508 \mathrm{~cm}^{-1}$ doublet is observed in the 


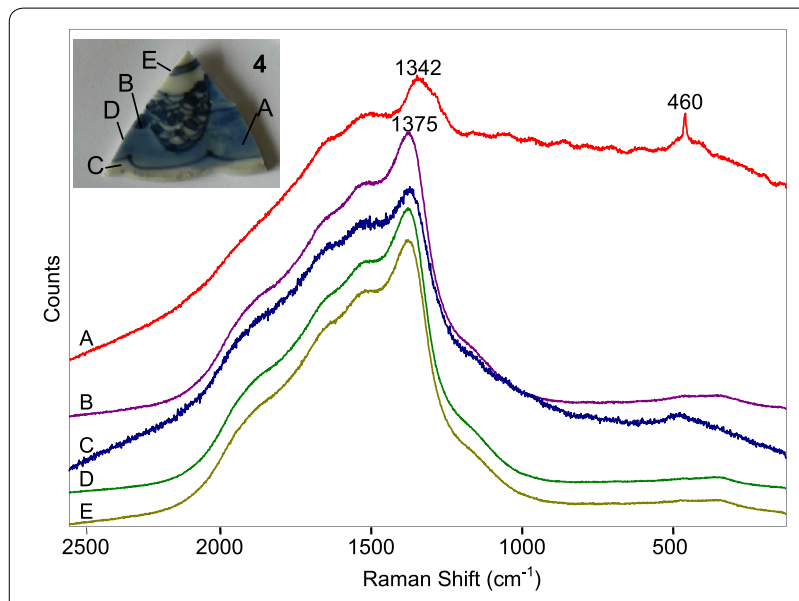

Fig. 6 Raman spectra collected from shard \#4 from the Santa Maria Madre de Deus. (A) Carbon, quartz (B) to (D) luminescence from REE, (E) luminescence from REE (shard edge). Spectra are to scale and have been offset for clarity

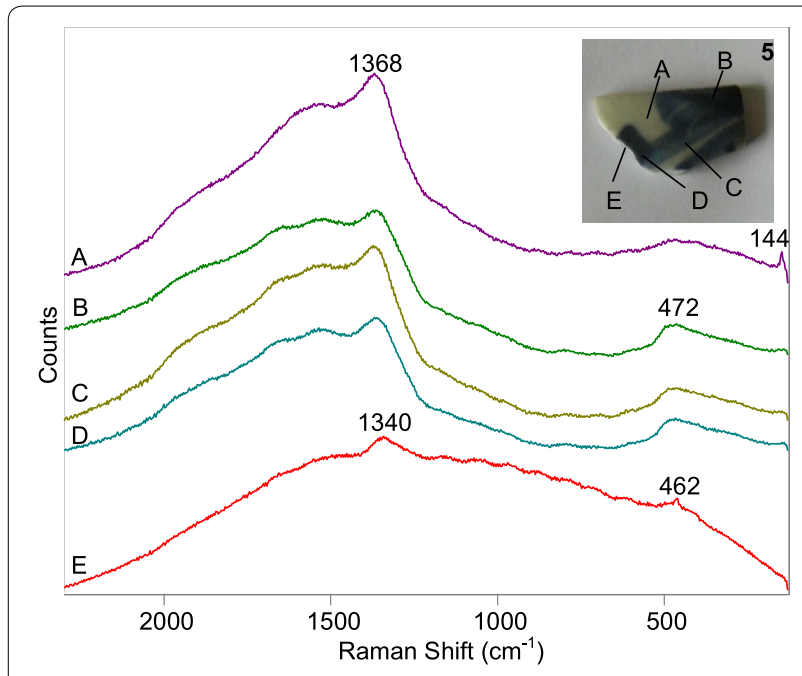

Fig. 7 Raman spectra collected from shard \#5 from the Santo Espirito. (A) Anatase, luminescence from REE, (B) luminescence from REE, (C) luminescence from REE, (D) luminescence from REE (shard back), (E) quartz and carbon (shard edge). All spectra are to scale, baseline corrected and are offset for clarity

spectra collected from both the blue and white areas of the shards (Figs. 2b, 3b, 5). It is therefore more likely that the bands are due to the presence of feldspar in the porcelain body. Any additional experimentation in the future would benefit from this use of $x$-ray diffraction, if available, to confirm this assignment. A list of characteristic Raman bands for typical components of Chinese and other porcelains is given in Table 1 and Table 2 presents a summary of materials found within the investigated shards.
Darker and paler blue colours were achieved using carbon and a white pigment, respectively; the presence of rutile as a white pigment was previously detected in the pale blue colour in a shard from the São Bento, which was wrecked off Msikaba, East Cape, in 1554, and gave rise to the conclusion that this stable, high temperature polymorph of titanium (IV) oxide was produced from the less stable anatase by high firing temperatures in the kiln [10]. No evidence of rutile with the characteristic strong doublet at $\sim 610$ and $445 \mathrm{~cm}^{-1}$ were observed in these spectra. Although amorphous carbon has been observed in the spectra collect from other Ming porcelain samples $[10,14,17]$ it was not observed in the data collected from these samples.

In Figs. 2, 3 and 5 the presence of anatase is clearly observed with characteristic bands at 638, 398 and $143 \mathrm{~cm}^{-1}$ [18]. Anatase is a component of the kaolin china clay and is a strong Raman scatterer; it is converted to rutile at temperatures ranging from 400 to $1200{ }^{\circ} \mathrm{C}$ and therefore its presence provides a good estimate of kiln temperatures [19-22]. Although it is recorded in the literature of artists' pigments that anatase is a twentieth century pigment, its presence in ancient Chinese porcelains as a component of kaolin is well-founded from Raman spectroscopic data [23, 24]. Further evidence to support that shards \#1 and \#3 were subjected to lower kiln firing temperatures is the presence of $\beta$-wollastonite in the porcelain body $[3,25]$ with bands observed at $\sim 971,638$ and $340 \mathrm{~cm}^{-1}$. $\beta$-Wollastonite is a characteristic marker used to discrimination between soft- and hard-paste porcelains. To date there is no literature which cites the presence of $\beta$-wollastonite in Ming Dynasty (1368-1644 AD) period porcelain; although it has been found in a range of other samples including sixteenth century Medici [8] as well as a number of eighteenth and nineteenth century French porcelains $[3,25]$.

Other interesting spectral features of shards \#1 and 3 are observed with the $2000-1300 \mathrm{~cm}^{-1}$ region in Figs. 2, 3 and 5. It has been recognised that when using an NIR excitation source for analysis of glasses, glazes and ceramics that a broad somewhat featureless luminescence is often observed. This has been attributed to the excitation of electronic transitions of rare earth elements [8, 26]. However, the spectra shown in Figs. 2, 3 and 5 have significantly more structure and bare a great similarity to recent data published by Widjaja et al. [17] who investigated a range of glazed and unglazed Yuan, Ming and Qing shards using a combination of Raman microspectroscopy and band-target entropy minimization (BTEM) which is a self-modeling curve resolution technique. The analysis of over 3700 spectra collected using an excitation wavelength of $785 \mathrm{~nm}$ resulted in the reconstruction of six pure component spectra. One of these components 
Table 1 Characteristic Raman bands of components in Chinese porcelains and related materials $[14,30,31]$

\begin{tabular}{ll}
\hline Component & Characteristic Raman bands $\left(\mathbf{c m}^{\mathbf{- 1}}\right)$ \\
\hline a-Wollastonite & $370 \mathrm{w}, 578 \mathrm{~s}, 985 \mathrm{~s}, 932 \mathrm{w}, 1073 \mathrm{w}$ \\
B-Wollastonite & $410 \mathrm{~ms}, 635 \mathrm{~ms}, 980 \mathrm{~s}$ \\
Calcium phosphate & $415 \mathrm{~m}, 970 \mathrm{~s}$ \\
Mullite & $302 \mathrm{w}, 480 \mathrm{~m}, 600 \mathrm{dr} \mathrm{ms}, 960 \mathrm{~m}, 1130 \mathrm{mw}$ \\
a-Quartz & $194 \mathrm{w}, 464 \mathrm{~s}$ \\
Rutile & $144 \mathrm{w}, 240 \mathrm{mw}, 441 \mathrm{mw}, 606 \mathrm{mw}$ \\
Anatase & $143 \mathrm{~s}, 197 \mathrm{w}, 398 \mathrm{~m}, 517 \mathrm{~m}, 641 \mathrm{~m}$ \\
Brookite & $153 \mathrm{w}, 245 \mathrm{mw}, 320 \mathrm{mw}, 364 \mathrm{mw}, 449 \mathrm{w}$ \\
Calcite & $151 \mathrm{~m}, 283 \mathrm{~ms}, 712 \mathrm{mw}, 1086 \mathrm{~s}$ \\
Aragonite & $140 \mathrm{mw}, 203 \mathrm{~m}, 705 \mathrm{~m}, 1086 \mathrm{~s}$ \\
Cristobalite & $230 \mathrm{mw}, 420 \mathrm{~m}$ \\
Cobalt blue & $190 \mathrm{w}, 280 \mathrm{w}, 404 \mathrm{mw}, 485 \mathrm{~m}, 506 \mathrm{~ms}, 560 \mathrm{w}$ \\
Carbon & $1320 \mathrm{br} \mathrm{ms}, 1585 \mathrm{br} \mathrm{ms}$ \\
Feldspar & $510 \mathrm{~m}, 960 \mathrm{~s}$ \\
Hematite & $229 \mathrm{~m}, 299 \mathrm{~m}, 409 \mathrm{~ms}, 640 \mathrm{~m} \mathrm{br}$ \\
\hline
\end{tabular}

$W$ weak, $m$ medium, $s$ strong, br broad, $m s$ medium to strong, $m w$ medium to weak

Table 2 Summary of materials found in porcelain shards from two Portuguese shipwrecks

\begin{tabular}{|c|c|c|}
\hline Portuguese carrack & Sample & Components \\
\hline \multirow[t]{4}{*}{$\begin{array}{l}\text { Santa Maria Madre de Deus } \\
\text { (1643) }\end{array}$} & Shard \#1 & $\begin{array}{l}\text { Feldspar, anatase, } \\
\beta \text {-wollastonite, ilmenite or } \\
\text { Ilm-Hem } \text { ss' }^{\prime} \text { calcite (data not } \\
\text { shown), luminescence due } \\
\text { to REE }\end{array}$ \\
\hline & Shard \#2 & $\begin{array}{l}\text { a-Quartz, ilmenite or IIm- } \\
\text { Hem } \text { ss, amorphous carbon, }_{\text {anatase, hematite }}\end{array}$ \\
\hline & Shard \#3 & $\begin{array}{l}\text { Feldspar, anatase, } \\
\beta \text {-wollastonite, luminescence } \\
\text { due to REE }\end{array}$ \\
\hline & Shard \#4 & $\begin{array}{l}\text { Amorphous quartz, lumines- } \\
\text { cent profile of glaze, a-quartz }\end{array}$ \\
\hline Santo Espirito (1608) & Shard \#5 & $\begin{array}{l}\text { Anatase, amorphous quartz, } \\
\text { luminescent profile of glaze, } \\
\text { a-quartz }\end{array}$ \\
\hline
\end{tabular}

IIm-Hem ${ }_{s s}$ ilmenite hematite solid solution

was attributed to lanthanide complexes which undergo resonance enhancement when using a NIR source.

The spectrum presented in Fig. 2f, with an expanded spectral region shown in Fig. 3f, is dominated by a broad intense peak at $680 \mathrm{~cm}^{-1}$ with a range of weaker features observed at 371,332 and $222 \mathrm{~cm}^{-1}$. This spectral pattern is characteristic of a range of $\mathrm{Fe}-\mathrm{Ti}-\mathrm{Cr}$ oxides with the exception of hematite which is dominated by strong features within the $300-200 \mathrm{~cm}^{-1}$ spectral region. The spectrum presented in Fig. $2 \mathrm{f}$ is most similar to that of ilmenite although the peak positions noted earlier are not an exact match with literature [27-29]. At temperatures above $960{ }^{\circ} \mathrm{C}$ it is known that ilmenite and hematite can form a solid solution ( $\mathrm{Ilm}-\mathrm{Hem}_{\mathrm{ss}}$ ), with the critical temperature at which the components are miscible in all proportions being $\sim 650{ }^{\circ} \mathrm{C}$ [29]. Hematite was found in shard \#1 (data not shown) and the spectrum in Fig. 4c collected from shard \#2 has been tentatively assigned to hematite, therefore it is a possibility that the collected spectra are from an ilmenite-hematite solid solution. The identification of this mineral could be confirmed with X-ray diffraction if any future studies are undertaken. Although multiple areas of the shards were interrogated ilmenite, or Ilm-Hem ${ }_{\mathrm{ss}}$, was found only in shards \#1 and \#2. Interestingly, both spectra were collected from darkly coloured particles, one within one of the blue strips of shard \#1 and the other within the white area of shard \#2. This raises the question of whether ilmenite was a minor component of the porcelain body or was it added to the blue pigment to produce a darker shade of blue?

\section{Shards \#2, \#4 from the Santa Maria Madre de Deus and \#5 from the Santo Espirito}

Figure 4 presents a range of spectra collected from various regions of shard \#2 which was glazed. Not surprisingly similar components found in shards \#1 and \#3 were found in this sample including $\alpha$-quartz (Fig. 4a, e), ilmenite/Ilm-Hem ${ }_{\text {ss }}$ (Fig. 4b), and anatase (Fig. 4e). The Raman spectra also exhibited broad features at $\sim 1563$ and $1329 \mathrm{~cm}^{-1}$ which could be attributed to carbon found on the shard edge (Fig. 4b). The spectrum shown in Fig. $4 \mathrm{c}$ is tentatively attributed to hematite $(595,403$, 292, $222 \mathrm{~cm}^{-1}$ ) [14] but the bands observed at 663,200 and $151 \mathrm{~cm}^{-1}$ remain unassigned. Raman spectra collected from the glazed shards numbered \#4 (Fig. 6) and \#5 (Fig. 7) are dominated by the luminescent profile of the glaze with weak bands of $\alpha$-quartz and anatase also observed. A band of medium intensity centred at $\sim 472 \mathrm{~cm}^{-1}$ is assigned to the $\mathrm{Si}-\mathrm{O}$ bending modes of the glaze [13].

\section{Conclusions}

Raman spectroscopic analysis of several shards recovered from two Portuguese shipwrecks, 1608-1643, believed to be carrying porcelains of the Ming period have revealed some interesting and novel results that inform historical ideas of porcelain production. Although the spectra generally reinforce earlier studies from similar material recovered from other shipwrecks off the Cape of Good Hope, South Africa, in the period 1554-1650, some noteworthy differences are observed here. The detection of anatase almost exclusively in the porcelain bodies rather than rutile, the higher temperature stable form 
of titanium (II) oxide, indicates lower kiln temperatures. The discovery of $\beta$-wollastonite characteristic of softpaste porcelains further suggests two of the shards (\#1 and \#3) being subjected to lower kiln temperatures. To date there are no studies which have found $\beta$-wollastonite in Ming period samples. Are these samples "interlopers" or are they are reflection of changes in the body composition of Ming factory porcelain production in its final years. It was quite common practice for other porcelain manufactories to experiment with their body composition and kiln conditions in an effort to minimise kiln wastage and in the search for higher quality; examples of this practice are the addition of glass frit to porcelains before firing to increase translucency-this was achieved but in practice such glassy porcelains were always rather unstable and kiln losses were significantly higher before bone ash made an entrance as a component.

\section{Abbreviations}

BC: Before Christ; BTEM: band-target entropy minimization; DP: degree of polymerisation; NIR: near infrared; REE: rare earth elements.

\section{Authors' contributions}

HGME and DDW were involved in the initial concept of the experiments. EAC and MW collected the data used in this paper. EAC and HGME equally contributed to data analysis, interpretation and manuscript writing. All authors read and approved the final manuscript.

\section{Author details}

${ }^{1}$ Vibrational Spectroscopy Core Facility, The University of Sydney, Sydney, NSW 2006, Australia. ${ }^{2}$ The School of Chemistry, The University of Sydney, Sydney, NSW 2006, Australia. ${ }^{3}$ Department of Chemistry, University of Pretoria, Pretoria 0002, South Africa. ${ }^{4}$ Chemical \& Forensic Sciences, School of Life Sciences, University of Bradford, Bradford BD7 1DP, UK.

\section{Acknowledgements}

The authors would like to thank the Dr. Valerie Esterhuizen is thanked for supplying the ancient samples and historical background. The authors acknowledge the facilities of the Vibrational Spectroscopy Core Facility at the University of Sydney. DdW acknowledges the financial support by the University of Pretoria and the NRF, Pretoria.

\section{Competing interests}

The authors declare that they have no competing interests.

\section{Funding}

This research was supported by the Australian Research Council (ARC International Linkage: LX0776464 and ARC LIEF: LE0883036 Grants).

Received: 23 December 2016 Accepted: 21 March 2017 Published online: 04 May 2017

\section{References}

1. Chalmers JM, Edwards HGM, Royal Society of C. Raman spectroscopy in archaeology and art history. Cambridge: Royal Society of Chemistry; 2005

2. Vandenabeele P, Edwards HGM, Moens L. A decade of Raman spectroscopy in art and archaeology. Chem Rev. 2007;107(3):675-86.

3. Colomban P, Treppoz F. Identification and differentiation of ancient and modern European porcelains by Raman macro- and micro-spectroscopy. J Raman Spectrosc. 2001;32(2):93-102.
4. Colomban P, Sagon G, Faurel X. Differentiation of antique ceramics from the Raman spectra of their coloured glazes and paintings. J Raman Spectrosc. 2001;32:351-60.

5. Liem NQ, Thanh NT, Colomban P. Reliability of Raman micro-spectroscopy in analysing ancient ceramics: the case of ancient Vietnamese porcelain and celadon glazes. J Raman Spectrosc. 2002;33(4):287-94.

6. Michel D, Colomban P, Abolhassani S, Voyron F, Kahn-Harai A. Germanium mullite: structure and vibrational spectra of gels, glasses and ceramics. J Eur Ceram Soc. 1996;16(2):161-8.

7. Colomban P. Differentiation of antique porcelains, celadons and Faiences from the Raman spectra of their bodies, glazes and paintings. Asian Chem Lett. 2001;5:125-33.

8. Colomban P, Milande V, Lucas H. On-site Raman analysis of Medici porcelain. J Raman Spectrosc. 2004;35(1):68-72.

9. Eccles H, Rackham B. Analysed specimens of English porcelain. London: Victoria \& Albert Musuem; 1922.

10. de Waal D. Raman investigation of ceramics from 16th and 17th century Portuguese shipwrecks. J Raman Spectrosc. 2004;35(8-9):646-9.

11. Nicholson R, Butler A. White gold. Chem Br. 1997;33(2):25-7.

12. Vainker $S$. Chinese pottery and porcelain: from prehistory to the present. London: British Museum Press; 1991.

13. Colomban P. Case study: glasses, glazes and ceramics—recognition of ancient technology from the Raman spectra. In: Edwards HGM, Chalmers JM, editors. Raman spectroscopy in archaeology and art history. New York: Marcel Dekker; 2000. p. 192-206.

14. Kock LD, De Waal D. Raman studies of the underglaze blue pigment on ceramic artefacts of the Ming dynasty and of unknown origins. J Raman Spectrosc. 2007;38(11):1480-7.

15. Wood N. Chinese glazes: their origins, chemistry and recreation. London: A\&C Black Publishers Ltd; 1999.

16. de Waal D. Raman identification of the pigment in blue and white Ming porcelain shards. Asian Chem Lett. 2004;8:57-65.

17. Widjaja E, Lim GH, Lim Q, Mashadi AB, Garland M. Pure component Raman spectral reconstruction from glazed and unglazed Yuan, Ming, and Qing shards: a combined Raman microscopy and BTEM study. J Raman Spectrosc. 2011;42(3):377-82.

18. Edwards HGM, Nik Hassan NF, Middleton PS. Anatase-a pigment in ancient artwork or a modern usurper? Anal Bioanal Chem. 2006;384(6):1356-65.

19. Kim D-W, Kim T-G, Hong KS. Origin of a shrinkage anomaly in anatase. J Am Ceram Soc. 1998;81(6):1692-4.

20. Liu L-G, Mernagh TP. Phase transitions and Raman spectra of anatase and rutile at high pressures and room temperature. Eur J Miner. 1992:4(1):45-52.

21. Hanaor DAH, Sorrell CC. Review of the anatase to rutile phase transformation. J Mater Sci. 2011:46(4):855-74.

22. Liem NQ, Sagon G, Quang VX, Tan HV, Colomban P. Raman study of the microstructure, composition and processing of ancient Vietnamese (proto) porcelains and celadons (13-16th centuries). J Raman Spectrosc. 2000;31(10):933-42.

23. Zuo J, Xu C, Wang C, Yushi Z. Identification of the pigment in painted pottery from the Xishan site by Raman microscopy. J Raman Spectrosc. 1999:30(12):1053-5.

24. Jian Z, Changsui W, Cunyi X. Non-destructive in-situ study of white and black coating on painted pottery Sherds from Bancun site (Henan, China) by Raman microscopy. Spectrosc Lett. 1998;31(7):1431-40.

25. Mancini D, Dupont-Logié C, Colomban P. On-site identification of Sceaux porcelain and faience using a portable Raman instrument. Ceram Int. 2016;42(13):14918-27.

26. Carter EA, Kelloway SJ, Kononenko N, Torrence R. Raman spectroscopic studies of Obsidian. Analytical archaeometry. London: The Royal Society of Chemistry; 2012. p. 318-44.

27. Rull F, Martinez-Frias J, Rodríguez-Losada JA. Micro-Raman spectroscopic study of El Gasco pumice, western Spain. J Raman Spectrosc 2007;38(2):239-44.

28. Lafuente B, Downs RT, Yang H, Stone N. The power of databases: the RRUFF project. In: Armbruster T, Danisi Rosa M, editors. Highlights in mineralogical crystallography. Berlin: W. De Gruyter; 2015. p. 1-30.

29. Wang A, Kuebler KE, Jolliff BL, Haskin LA. Raman spectroscopy of Fe-Ti-Cr-oxides, case study: Martian meteorite EETA79001. Am Miner. 2004;89(5-6):665-80 
30. Caggiani MC, Acquafredda P, Colomban P, Mangone A. The source of blue colour of archaeological glass and glazes: the Raman spectroscopy/SEMEDS answers. J Raman Spectrosc. 2014;45(11-12):1251-9.
31. Colomban P. Raman spectrometry, a unique tool to analyze and classify ancient ceramics and glasses. Appl Phys A. 2004;79(2):167-70
Submit your manuscript to a SpringerOpen ${ }^{\ominus}$ journal and benefit from:

- Convenient online submission

- Rigorous peer review

- Immediate publication on acceptance

- Open access: articles freely available online

- High visibility within the field

- Retaining the copyright to your article

Submit your next manuscript at $\boldsymbol{\nabla}$ springeropen.com 